\title{
Study on the Service Awareness of Advisor Expressed in the Employment Guidance for College Students
}

\author{
Yang Xu \\ Hubei University of Medicine; Shiyan Hubei 442000 China
}

\begin{abstract}
Keywords: College students'; Employment; Advisor; Service awareness.
\end{abstract}
\begin{abstract}
The continuing enrollment expansion of our colleges and universities and increasing college students have exerted negative effect on the college students' employment. And the difficult employment situation is still disturbing the college, society, family and student, while Advisor, as the direct participator and coordinator of employment guidance work, more need to strengthen the help with college students' employment in the real work. They are supposed to transform traditional working methods and strengthen the service awareness of student work to establish the effective employment bridge for students and guide students to constantly study and improve their own professional quality. And they should fully make the college resource construction best and offer better approaches to the future development of students.
\end{abstract}

\section{Introduction}

Advisor are the significant teachers except for the teaching teachers and other managers for the vocational college students, but the construction level of advisor team is not still mature, which results in the not high team comprehensive quality and inferior structure stability of current college advisor team. They cannot cause continuous education and influence on students and provide effective management and implement advice aiming at the related problems of student employment. At the same time, the members of Advisor in the vocational colleges vary greatly, which cannot be standard in the practical working effect. All these lead to the urgent optimization of team structure of college Advisor and add some modern managing methods and concepts through overall optimization.

\section{Meaning of Advisor in the Employment Guidance for College Students}

\subsection{Beneficial to Guaranteeing the Employment Development of College Students}

College Advisor can provide students with the information service and latest and accurate employment market information to strengthen the corresponding abilities and realize their own value in the work as soon as possible. For this respect, it is of great significance to the promotion of college employment development through constantly improve the college employment service and offering employment help.

\subsection{Promote the Information Exchange Between the College and Enterprise}

The advisor plays a role in communicating the information between the college and enterprise. The assessment of Advisor with the relevant professions and student ability can provide accurate talent information for the enterprises of society and a more convenient way for college employment. Advisor' work can be closer with the real demand of students in this department and enterprises for the talents. So, it will greatly promote the convenience degree in the students' employment and get through the information channel of human resource.

\subsection{Good for the Ordered Promotion of Realizing College Students' Promotion}

Advisor can offer the employment resources to students and help them analyze the condition and strengthen basic skills, also making the good connection between the demand of students and social work to better serve students in the employment guidance. The ever advisor employment guidance lacked of the supervision and harmony, so the efficiency was always very low due to the shortage of time and capital. In addition, students cannot get useful help. Few students successfully got the job by 
the means of campus recruitment, namely, the problem of "the graduation equals to the unemployment" is relatively severe. While Advisor can achieve the accurate connection between the recruitment resource of enterprises and relevant talent realization through the communication and coordination of all the resources to better know the demand of them explicitly. What's more, they should promote the employment work in accordance with the working arrangement during the graduation period to realize the steady transition in the employment of college students.

\section{Specific Contents of Advisor' Service Awareness}

\subsection{Provide Students with Timely and Accurate Employment Information}

The Ministry of Education lawfully regulated the behavior of college Advisor ten years ago, and it explicitly requires that Advisor should offer certain employment guidance service and effective employment information to college students. In addition, they should contact with the related enterprises to recruitment and realize the information guarantee of college students in the employment and job selection. The information service of Advisor to students is a significant service project in the employment service, but current Advisor lack the work ability and key personalities, for instance, personal quality and character (including the manner of dealing with people, anti-pressure ability and physical and mental health), professional quality (responsibility awareness and good attitude), knowledge ability (psychological basic knowledge, ideological and political education knowledge and literature and pedagogy knowledge) and work ability (ability of coordination and communication, organization and management ability and response ability). And all of these cause Advisor' inferior ability to practically provide service and they cannot better manifest the accurate transition of employment information and specific analysis demand of employment market.

\subsection{Make the Professional Psychological Guidance for Students}

Currently, the imperfect psychological health education for college students mainly manifest the corresponding course setting, and the not clear countermeasures to achieve good mental health mainly show that the disadvantages of corresponding mental health consult content and specific connotation lay the hidden danger for the unsound college mental health education system. And the members and contents of mental health education cannot give full play to their own effect. What's more, lacking the specific and detailed system for the specific mental education part has caused that students are not able to better devote themselves to the work or new work chance due to the inner pressure and disorientation when facing the problem of employment. However, most current colleges have such problems, for example, making the selection according to the difficulty level of professional quality training content, and college psychological teachers lack the senior teaching experience, which causes the former psychological course teaching lack certain fresh sense. And colleges fail to consider students' avoidance, so the practical teaching course are a little childish and imbalanced. All of these are the result of imperfect mental health education for college students. Unsound mechanism will make quite a few college students fail to express the sense of achievement brought by the consistency of mental education in the practical mental problems.

\subsection{Make the Corresponding Guidance and Education with Students' Employment Concept}

Lots of college students adopt the avoiding and negative attitude towards the increasing social employment pressure, and some college students choose to take the exam for post-graduate blindly and some students take advantage of varieties of tests to avoid the reality of entering society and work. As for the students, their employment concept has not been correctly established yet, so they don't have the experience in society to a great extent. So, some students think that employment is just to make money, but they are not aware that the deviance of employment concept has influenced their future development. And this requires that Advisor should positively teach and guide students with the employment concept, for example, making the analysis of the difference between the differentiated entrepreneurship and traditionally hunting job. The former compensated many disadvantages of the traditional entrepreneurship, which can lay the foundation for many people who are eager to have their own enterprises. And it has numbers of advantages, for instance, low cost, high 
invest-return rate and relatively simple starting procedure. And compared with the argument and audition of formal enterprises, it has a smaller running size, usually serving limited group and oriented with fixed clients, for example, the rather popular "we-chat business", as one of the models widely accepted by the Internet entrepreneurship, just needs a small cost, even to hundred or thousand yuan, which greatly lowers the threshold and guarantee the problem of money loss most people would worry about in the beginning. The great improvement of entrepreneurship rate also gives many young people the chance and platform to attempt and develop. Advisor can explain the fresh practical case to students and make students clearly know how to make their contributions to their own employment channel. It can better express the professional characteristic of Advisor.

\section{How to Strengthen the Service Awareness of Advisor in the Employment Guidance}

\subsection{Scientific Performance Reward and Pay Attention to the Comprehensive Development of Advisor}

Advisor team plays a significant role in the fundamental education in the higher vocational colleges, and its performance reward mechanism is hard to innovate in the existing model, so the construction with performance reward mechanism in the higher vocational college for the several years is of no practical meaning. However, scientific performance assessment is the significant point to guarantee the successful implementation of enterprise operation management measures, and performance is the exact guarantee of personal economy interest of current Advisor. Rational performance level is the main resource of Advisor' salary. In the modern higher education system, various reward methods are not deeply applied, for example, the salary reward, expression reward and assessment reward, due to the condition of false staff performance and not clear reward mechanism. Such conditions bring many disturbances for those Advisor who want to realize greater vocational development through performance reward mechanism. In order to solve the problem, many higher vocational colleges make the performance distribution systematic and set the allocation details through designing rational performance guarantee measures including the assessment with performance and the responsible person. They let the specific person check and record and improve the application of various reward mechanism according to the former work and salary conditions to realize the performance reward mechanism with level and difference and to a great extent realize the perfect development of advisor team and promote them serve the employment guidance for college students.

\subsection{Connect the College with Enterprise and Accurately Dock the Demand of Enterprises and Students}

Advisor play the role of bridge between the enterprises and students, which means that the connection of colleges and enterprises are of great significance to the employment of college students. In this process, Advisor should make the whole situation as the first and better coordinate with the inner part of enterprise. The recruitment of enterprises usually represents the developing trend of corresponding field. And Advisor are supposed to accurately understand the relevant change of recruitment procedure and concept of different enterprises and timely convey them to students to help students get ready for better adapting to the recruitment of enterprises and work.

They should learn the excellent recruitment system from the international enterprises and realize the strategic recruitment plan. Strategic plan system reflects the enterprise management work, so it should be entered from various angels and learn the advanced managing experience of western enterprises, from the recruitment members allocation to the management procedures and rules. Such methods can mend the track of enterprise development and go towards the higher target and accelerate the management effectiveness. In addition, the recruitment plan of medium and small enterprises should be based on the human resource plan and understand the recruitment time period, number and types and quality of talents through human resource plan. Recruitment plan should connect the inner and outside factors, and the inner factors include recruitment posts, plan, time and period and number; while the outside factors include the selection of proper recruitment channel, designing and teasing 
the recruitment procedures, assessment and prediction with recruitment market and fee prediction produced by the recruitment and assessment with recruitment effect. The scientific and rational recruitment plan should be formulated through the above contents to realize the human resource needed by the enterprise and promote the rapid development and target realization of enterprises.

\subsection{Promote the Professional Construction}

Professional construction is the important direction of future advisor team. And the profession refers to the business ability, attitude and working environment. Due to the inferior comprehensive college condition and imperfect fundamental infrastructure construction and facilities, Advisor' knowledge, ability and work attitude are not well assessed and restrained. At the same time, most Advisor don't have specific office and consult place, so the atmosphere lacking profession hinders the guidance ability and enthusiasm of Advisor when making the specific research with students' employment condition. Therefore, colleges should constantly strengthen the professional continuing study and training in constructing the future advisor team. And those Advisor with stronger ability should be provided the good promotion mechanism and the whole advisor team is supposed to be encouraged to develop upward.

\subsection{Create the Learning Advisor Team}

Colleges should create the proper profession plan for the advisor team according to their specialties and practical guidance ability, for instance, establishing carious advisor work team: the consulting team of course, mental health and entrepreneurship. Establishing learning team also needs to establish the corresponding learning forum based on the own characteristic and regularly exchange and learn the experience and the specific methods applied to the practical work. Colleges should pay enough attention to the work of Advisor and guide them have regular report and communication to expose the key and difficult points in the student management work and discuss better solution to comprehensively strengthen the guidance ability.

In the meanwhile, college Advisor should be equipped with a good contribution spirit, and their behaviors represent the spirit realm and ideological awareness of teachers. And their participation in the volunteering service at proper time also belongs to the good personal quality in the social behavior. Advisor should have their own ability and corresponding knowledge reservation when participating in students' employment guidance service. For instance, they are required to positively enhance their own knowledge level and ability to analyze the employment trend and direction of students when they lead students to join the practice. At the same time, college Advisor should positively take part in the related employment lecture or forum and study with students. Constant absorption with the new knowledge about employment and entrepreneurship can exert positive effect on the mentality of college teachers and help them form the good virtue of contribution. Also, the corresponding learning with practical cases can help college teachers learn the change of related fields in the recruitment process and have a significant effect on regulating their service with students' employment.

\section{Conclusion}

In summary, the problem of current college student employment is still severe, which needs wide advisor staff fully promote the spirit of collectivism and contribution and constantly strengthen the service awareness and enhance their own comprehensive qualities, to truly help college group, transmit more talents for the country and make their own contributions for the modern construction of socialism.

\section{References}

[1]. Yuguo Wang. Problems and Solutions Existing in the Current College Advisor Team Construction[J]. Journal of Qiqihar University: Natural Science, 2005, (5). 
[2]. Xueqin Zhang. Study on the Service Awareness of Advisor Expressed in the Employment Guidance for College Students[J]. Journal of Donghua University (Social Science Edition), 2015,15(02):102-104.

[3]. Lu Liu, Yan Yang, Jun Chen. Study on the Employment Guidance Working Mechanism of College Advisor — Taking the Example of Colleges in Guizhou Province[J]. Journal of Jiamusi Vocational College, 2016(07):250-252+254.

[4]. Zhongzhao Lu. Study on the Problems and Solutions Facing the Advisor in the Vocational Colleges under the New Circumstance[J]. Education Science \& Culture Magazine (Edition of Last Ten Day),2013(05):185-186. 